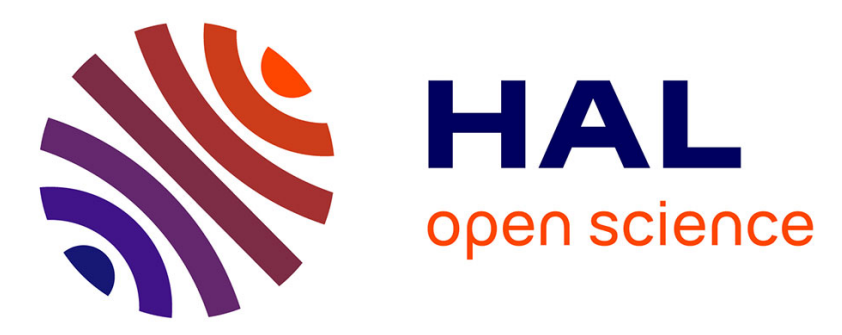

\title{
Sq solar variation at Medea Observatory (Algeria), from 2008 to 2011
}

\author{
F. Anad, Christine Amory-Mazaudier, M. Hamoudi, S. Bourouis, A. Abtout, \\ E. Yizengaw
}

\section{- To cite this version:}

F. Anad, Christine Amory-Mazaudier, M. Hamoudi, S. Bourouis, A. Abtout, et al.. Sq solar variation at Medea Observatory (Algeria), from 2008 to 2011. Advances in Space Research, 2016, 10.1016/j.asr.2016.06.029 . hal-01368924

\section{HAL Id: hal-01368924 \\ https://hal.sorbonne-universite.fr/hal-01368924}

Submitted on 20 Sep 2016

HAL is a multi-disciplinary open access archive for the deposit and dissemination of scientific research documents, whether they are published or not. The documents may come from teaching and research institutions in France or abroad, or from public or private research centers.
L'archive ouverte pluridisciplinaire HAL, est destinée au dépôt et à la diffusion de documents scientifiques de niveau recherche, publiés ou non, émanant des établissements d'enseignement et de recherche français ou étrangers, des laboratoires publics ou privés. 


\title{
Sq solar variation at Medea Observatory (Algeria), from 2008 to 2011
}

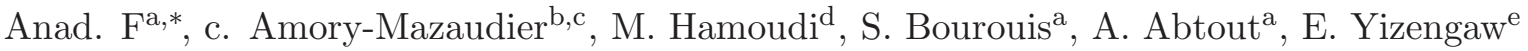 \\ ${ }^{a}$ Centre of Researcher in Astronomy, Astrophysic and geophysics. BP 63 Bouzareah, 16340 Algiers, Algeria \\ ${ }^{b}$ Sorbonne University, Paris VI, UPMC, LPP 5 place Jussieu, 75005 Paris, France \\ ${ }^{c} \mathrm{~T} / I C T 4 D$, the Abdus Salam International Centre for Theoretical Physics, Trieste, Italy \\ ${ }^{d}$ University of Sciences and Technology, Algiers, BP 32 El-Alia. Bab-Ezzouar, 16111 Algiers, Algeria \\ ${ }^{e}$ Institute for Scientific Research, Boston College, Boston, USA
}

\begin{abstract}
This paper presents the regular variations of terrestrial magnetic field recorded by a new magnetic observatory Medea, Algeria (geographic latitude: $36.85^{\circ} \mathrm{N}$, geographic longitude: $2.93^{\circ} \mathrm{E}$, geomagnetic latitude: $27.98^{\circ} \mathrm{N}$, geomagnetic longitude: $77.7^{\circ} \mathrm{E}$ ) during 2008-2011. The diurnal and seasonal variations of the solar quiet (Sq) variations are analyzed. The results show differences in the diurnal pattern of the northward-component Sq variation (SqX) at different seasons. The seasonal variation of SqX is similar in different years. The diurnal pattern of SqX from July through September cannot be explained by an equivalent current system that is symmetric about the noon time sector. The observations indicate that the major axis of the elliptic current system is tilted towards the equator in the morning hours during those months. The diurnal pattern of SqY indicates southward currents in the morning and northward currents in the afternoon, except during February-March 2009 when there is apparently no southward current during the morning. For the other months, the observations indicate that the maximum northward current intensity in the afternoon tends to be greater than the maximum southward current intensity in the morning. This is because of the UT variation of the Sq current system. That is, the pattern and strength of the Sq current system are different when $\mathrm{SqY}$ is measured in the morning around $8 \mathrm{UT}$ and in the afternoon around $14 \mathrm{UT}$. The amplitude of these extreme varies linearly with the solar cycle. For the SqY component, the changes in the morning maximum have an annual variation while that of the afternoon minimum has a semi-annual variation. These variations are attributed to seasonal variations in the ionospheric E-region conductivity and atmospheric tidal winds. The fieldaligned currents can also contribute to the seasonal variation of SqY. However, the two-dimensional approach used in this article does not allow us to quantitatively determine their influences.
\end{abstract}

Keywords: Transients Sq variations; geomagnetic field; ionosphere; Medea Observatory

\section{Introduction}

It is in 1722 that Graham discovered the existence of diurnal variation of regular terrestrial magnetic field. Later, Stewart (1882), in an attempt to explain this variation, proposed the existence of an ionized fluid circulating through the field lines of the terrestrial magnetic field. At that time the ionosphere had not yet been discovered. It was in 1901, that Marconi discovered the ionosphere with his transatlantic radio communication. The first soundings of the ionosphere were done by Breit \& Tuve (1926). In 1940 Chapman and Bartels developed the dynamo theory as known today.

Chapman \& Bartels (1940), using the classification given at Innsbruck of the magnetic quiet days, established electric current maps using the magnetic field variations averaged over the five

\footnotetext{
${ }^{*}$ Corresponding author

Email address: f_anad@yahoo.fr (Anad. F)
} 
quietest days of one month. This current system was named the Sq current system. The Sq current system is composed by two current vortices (one on each hemisphere), on the sunlit side of the Earth and centered on the local noon. The electric current flow is anticlockwise in the Northern hemisphere, and is clockwise in the Southern hemisphere. The Sq current has two components, internal and external components. While the external component is due to the ionospheric electric currents, the internal component is due to the telluric electric currents. The telluric electric currents are induced by ionospheric electric currents. Gauss (1839) invented a technique that enables the separation of the external and internal fields. Later studies applied the technique to the Sq field (Schuster, 1889; Price \& Wilkins, 1963).

Many experimental studies, based on ground magnetic data, were performed on Sq current systems during the International Geophysical Year (IGY) (e.g., Matsushita \& Maeda, 1965; Malin \& Gupta, 1977). Later on, Rastogi \& Iyer (1976), Campbell (1981) and Vassal (1982) analyzed the geomagnetic field at low latitudes. Campbell \& Matshushita (1982) compared Sq currents during quiet and active year. Stening (1971) and Chulliat \& al. (2005) characterized the longitudinal and seasonal variations of Sq currents. Takeda (1999) studied seasonal variations of Sq, separately for the solar maximum year of 1964 and the solar minimum year of 1980. Stening (1995) and Stening et al. (2005) analyzed the variation of Sq current strength, and the changes in the position of the foci of Sq current. At middle latitudes, Mayaud (1965), Davis \& al. (1965) and Torta et al. (1997), studied the variability of the Sq. More recently, in Africa, Middle East and Asia, Rabiu et al. (2009); Obiekezie \& Obiadazie (2013); Bolaji \& al. (2013); Abbas et al. (2013) and Pham et al. (2011), characterized the Sq current system. Satellite data are also used to study Sq current system; recently Pedatella et al. (2011) using CHAMP satellite data, performed the same study as Stening (1971) did during the last solar minimum.

Empirical models derived from ground magnetic data were elaborated by Doumouya \& al. (2003) on the equatorial electrojet and by Yamazaki et al. (2011), on the Sq. More studies on Sq current systems can also be found (e.g., Chapman, 1951, Matsushita \& Campbell, 1967, Maeda, 1968, and Campbell, 1989; Olsen (1993) and (1997). Mazaudier \& Blanc (1982) (1982) found systematic northward currents over most of the daytime hours; this fact was confirmed from a larger body of data (Mazaudier \& Venkateswran, 1985). Such northward asymmetry was previously found by Van Sabben (1964) and (1966). They found that this asymmetry is particularly strong in the European longitude sector.

More comprehensive studies were performed on the sources of the Sq, i.e. the neutral winds and the ionospheric electric currents. Richmond \& Roble (1987)and Richmond \& Thayer (2000) have described the Ionospheric electrodynamics. Hagan \& Forbes. (2002) and 2003 focused their studies on the migrating and non migrating tides in the upper atmosphere, see also Kelley (2009), and references therein.

This paper is devoted to the study of the monthly diurnal and seasonal variations of Sq currents using a new dataset from Observatory Medea in Algeria. Where a new magnetometer was installed in 2008 under the umbrella of AMBER project (Yizengaw \& Moldwin , 2009). The first section presents the data set and data processing technique, and the second section the results. The third section is a discussion of our results at the light of the preceding works with the conclusion.

\section{Data set and data processing}

The magnetic observatory at Medea $\left(36.85^{\circ} \mathrm{N}, 2.93^{\circ}\right.$ E geographic, $27.98^{\circ} \mathrm{N}, 77.7^{\circ}$ E geomagnetic) in Algeria was installed in 2008 under the umbrella of AMBER project (Yizengaw \& Moldwin 
, 2009), and is maintained by the Center of Research in Astronomy, Astrophysics and Geophysics (CRAAG, Algeria). In the framework of different scientific programs, United Nations Basic Space Science (UNBSS) International Heliophysical Year (IHY) and International Space Weather Initiative (ISWI), arrays of small instruments were deployed in order to make global measurements of space-physics-related phenomena. The network AMBER (African Meridian B field Education and Research) is one of the arrays of ground-based instruments deployed ini Africa under the IHY program (Yizengaw \& Moldwin, 2009). One of the objectives of the AMBER array is to address the processes that govern the electrodynamics of the equatorial ionosphere in the African sector.

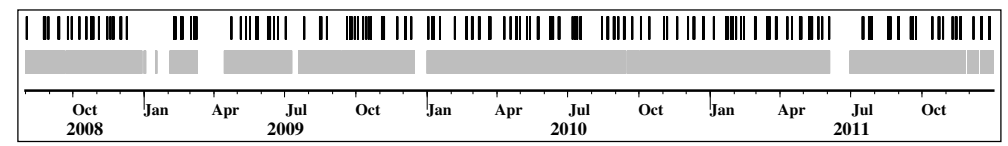

Figure 1: Data available at Medea station from August 2008 to December 2011. The gray and black colors correspond to the hourly and quiet d ays data, respectively.

The data set used in this study consists of the hourly values of geomagnetic components, North (X) and East (Y), recorded at Medea Observatory from August 2008 to December 2011. Figure 1 shows the available data; the grey and black correspond respectively to the hourly and the quiet days data. Table 1 gives the number of magnetic quiet days available for each month. The data are sampled at $2 \mathrm{~Hz}(0.5 \mathrm{sec})$ and are time tagged with an accuracy of $10^{-6} \mathrm{~s}$ (Yizengaw \& Moldwin , 2009). Then, these data are averaged to hourly values. The concept of local time (LT) was used throughout the analysis. Algeria is located at $(\mathrm{GMT}+1)$ longitudes.

Table 1: Magnetic quiet days available for each month.

\begin{tabular}{lllll}
\hline Month & $\begin{array}{l}\text { Available quiet } \\
\text { days (2008) }\end{array}$ & $\begin{array}{l}\text { Available quiet } \\
\text { days }(2009)\end{array}$ & $\begin{array}{l}\text { Available quiet } \\
\text { days (2010) }\end{array}$ & $\begin{array}{l}\text { Available quiet } \\
\text { days }(2011)\end{array}$ \\
\hline January & 0 & 0 & 5 & 5 \\
February & 0 & 4 & 5 & 5 \\
March & 0 & 4 & 5 & 5 \\
April & 0 & 1 & 5 & 5 \\
May & 0 & 5 & 4 & 5 \\
June & 0 & 4 & 5 & 1 \\
July & 0 & 2 & 5 & 5 \\
August & 5 & 4 & 5 & 4 \\
September & 4 & 5 & 4 & 4 \\
October & 5 & 5 & 2 & 2 \\
November & 4 & 3 & 3 & 5 \\
December & 3 & 3 & 5 & 5 \\
& $21 / 25$ & $40 / 60$ & $53 / 60$ & $51 / 60$ \\
\hline
\end{tabular}

The baseline value was deduced from the trend determined by the two local midnight levels on each side of the day [from 23.00 to $02.00 \mathrm{LT}$ ]. The baseline values for the elements used in this study are expressed as follows:

$$
M_{0}=\frac{M_{23}+M_{24}+M_{01}+M_{0} 2}{4}
$$


The hourly departures of $\mathrm{M}$ from midnight baseline, $(\Delta \mathrm{M})$, was obtained by subtracting the midnight baseline values for a particular day from the hourly values for that particular day. The hourly departure is expressed as follow:

$$
\Delta M_{t}=M_{t}-M_{0}
$$

where $\mathrm{t}$ is the time in hours, ranging from 01:00 to 24:00 LT. The hourly departure is further corrected for non-cyclic variation (Matsushita \& Campbell, 1967). Vestine (1947) have shown that the value at $01.00 \mathrm{LT}$ is different from the value at $24.00 \mathrm{LT}$. They proposed the correction of this non-cyclic variation by making a linear adjustment on the daily hourly values such that the $\mathrm{M}$ value at $01.00 \mathrm{LT}, 02.00 \mathrm{LT} \ldots 24.00 \mathrm{LT}$ are consider as N1, N2 ... N24 and taking:

$$
\Delta_{k}=\frac{N_{1}-N_{24}}{23}
$$

The linearly adjusted values at these hours are:

$$
N_{1}+0 \Delta_{k}, N_{2}+1 \Delta_{k}, \ldots \ldots \ldots \ldots N_{2} 4+23 \Delta_{k}
$$

The linearly adjusted values may be expressed as follows:

$$
\Delta M_{t}(N)=N_{t}+(t-1) \Delta_{t}
$$

The hourly departures corrected for non-cyclic variation give the solar daily variation in $\mathrm{X}$ and $\mathrm{Y}$. SqX and $\mathrm{SqY}$ denote the solar quiet daily variation in $\mathrm{X}$ and $\mathrm{Y}$ components during magnetic quiet days from August 2008 to December 2011.

The diurnal variation was obtained by averaging both $\mathrm{SqX}$ and $\mathrm{SqY}$ hourly values across the five international quiet days of each individual month.

The seasonal variations are also determined by calculating the average value of four months daytime values for each season. These seasonal variations are calculated following Lloyds seasons (Lloyd, 1861). The four months of the year are classified based on the three seasons: (1) December solstice or D-Season (January, February, November, and December), (2) Equinox or E season (March, April, September, and October), (3) June Solstice or J-Season (May to August). We have also separated the 2 equinoxes in spring equinox (March, April) and autumnal equinox (September, October).

Figure 2 gives the pattern of the ideal Sq current system (on the left) which is considered as fixed toward the Sun. During the day a magnetic observatory moves below this system of current. At the right of this figure the variations of $\mathrm{SqX}$ and $\mathrm{SqY}$ observed at the ground level are schematically illustrated.

In the Northern hemisphere $\mathrm{SqX}$ is nil at the focus of the Sq system. SqX is positive/Eastward ionospheric electric current above the focus (named model type E, pure maximum, by Mayaud, 1965 ). SqX is negative/Westward ionospheric electric current, below the focus of the Sq System (named model type $P$, pure minimum, by Mayaud, 1965). The $\mathrm{SqY}$, at all latitudes, is positive in the morning (Southward ionospheric electric current) and negative in the afternoon (northward ionospheric electric current). In the Southern hemisphere, it is the contrary as the current flows reverse compared to the northern hemisphere. We must recall here that the main pattern of Sq observed on data is roughly similar to this ideal pattern (Pham et al., 2011; De Michelis \& al., 2009; Torta et al., 2010). 


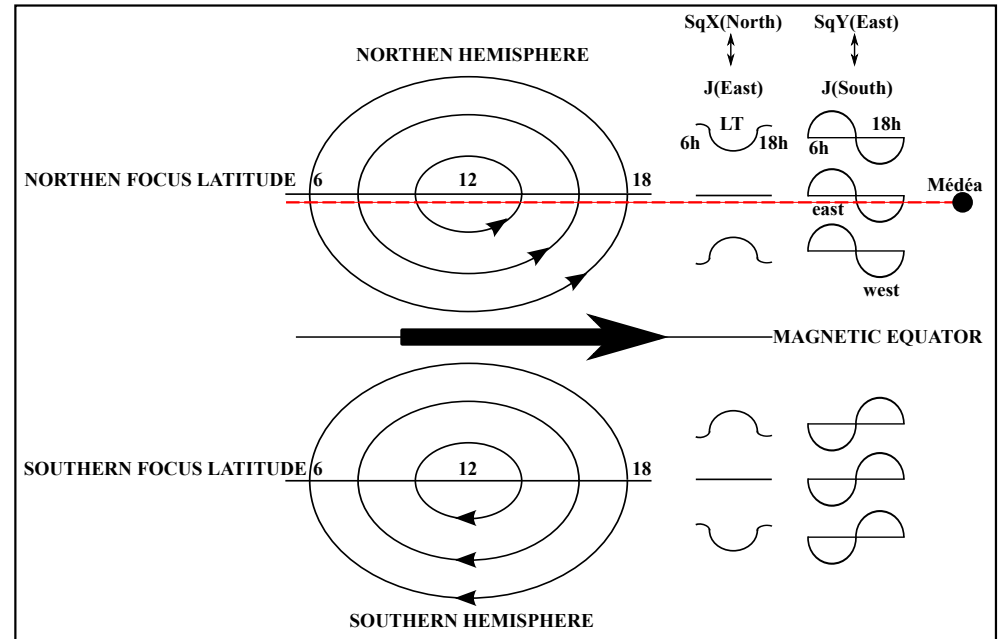

Figure 2: Sq current system schema (after Mazaudier, 1983). The current direction is anticlockwise in the northern hemisphere and clockwise in the Southern hemisphere, at the magnetic equator there is the equatorial electrojet. On the right side, the diurnal variations of $\mathrm{SqX}$ and $\mathrm{SqY}$, observed at ground level for different latitudes are drawn. Medea is located below the focus of the Northern vortex.

\section{Results}

\subsection{Diurnal variations:}

Figure 3a shows the daily variation of SqX at Medea for all the available magnetic quiet days from August 2008 to December 2011. This figure illustrates the day-to-day variability of SqX. The day-to-day variability is large, particularly from February to December. This figure highlights that variations of $\mathrm{SqX}$ are generally low during the night-time (from 18.00 LT to 00.06 LT) and oscillate between :5 nT and $3 \mathrm{nT}$. During the daytime we can observe three behaviors:

1) $\mathrm{SqX}$ is mainly positive from February to June. SqX reached its maximum, $37 \mathrm{nT}$, around 15.00 LT on May 25th, 2011.

2) SqX oscillates around zero from October to January. It reached its maximum value of $25 \mathrm{nT}$ around 12.00 LT on October 20th, 2008 and October 27th, 2009 respectively.

3) SqX exhibits negative values in the morning and positive values in the afternoon from July to September. The minimum value, $-35 \mathrm{nT}$, was reached at $10.00 \mathrm{LT}$ on September 19th, 2009 and the maximum value, $43 \mathrm{nT}$, was observed around 14.00 LT on September 1st, 2011.

Figure $\mathbf{3 b}$ is similar to Figure $\mathbf{3 a}$ for $\mathrm{SqY}$. The variations of $\mathrm{SqY}$ are generally low during the night-time and oscillates between $-5 \mathrm{nT}$ and $3 \mathrm{nT}$. We observe the same pattern for all the days with a maximum in the morning and a minimum in the afternoon, except during February-March 2009 , there is apparently no morning maximum. The morning maximum, $\sim 40 \mathrm{nT}$, was observed between 08.00-09.00 LT of April 27 and September 1st, 2011. The minimum value, $\sim-40 \mathrm{nT}$, was observed in the afternoon around $14.00 \mathrm{LT}$ on September 16th, 2011. The variability of $\mathrm{SqY}$ is smaller than that of SqX. 


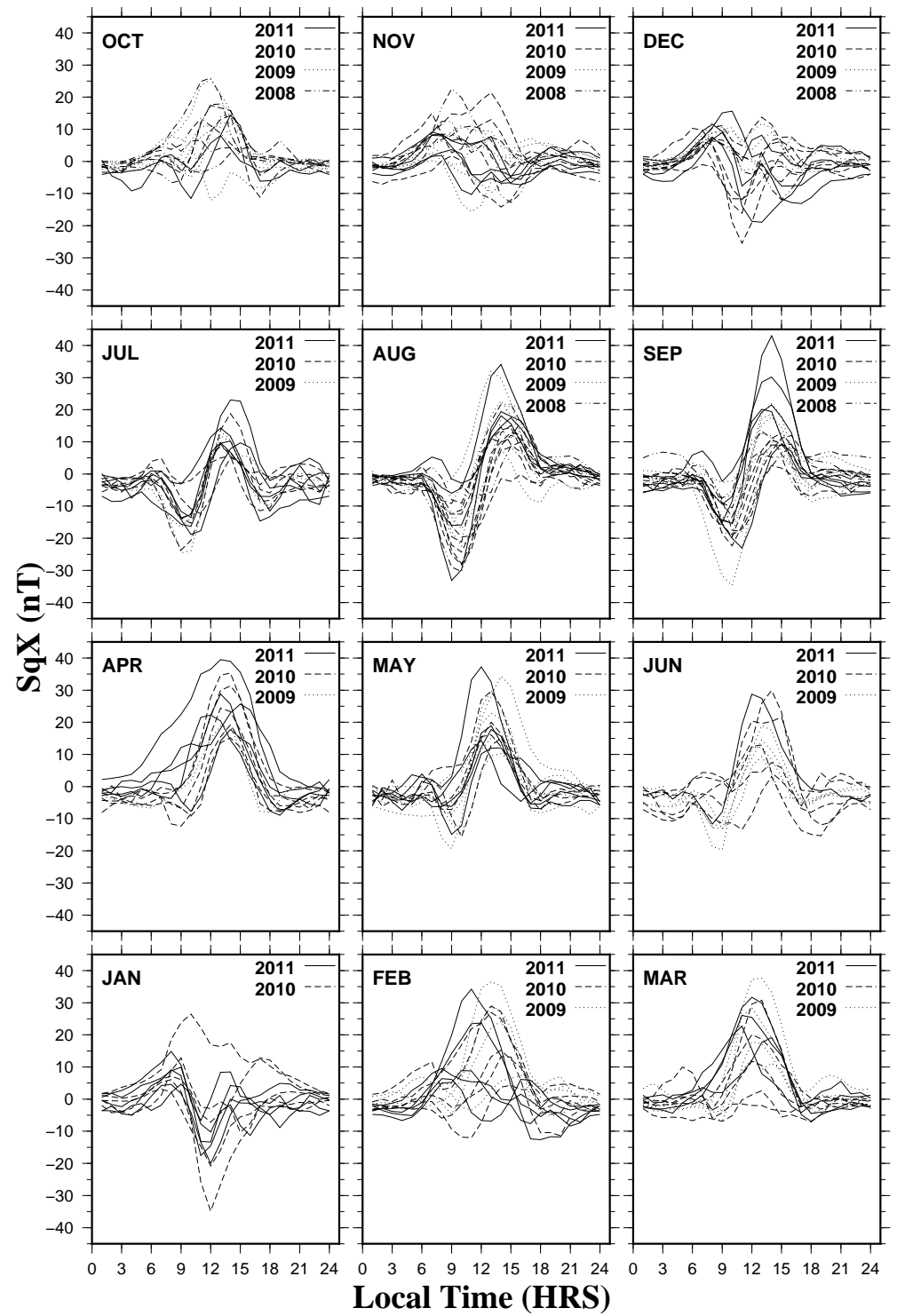

Figure 3a: The mass plot of diurnal variations of the SqX at Medea for all the available magnetic quiet days from August 2008 to December 2011.

\subsection{Monthly diurnal variations:}

Figure 4a shows the monthly diurnal variations of $\mathrm{SqX}$ for the 12 months during the years 2009, 2010, 2011 and several months in 2008. The variations of $\mathrm{SqX}$ are generally low during the night-time and oscillates between $-5 \mathrm{nT}$ and $0 \mathrm{nT}$. During the daytime, we can distinguish the same behaviors as on the individual days (Figure $\mathbf{3 a}$ ):

1) SqX is mainly positive from February to June, the maximum value of $\mathrm{SqX}, \sim 29 \mathrm{nT}$, was observed around 12.00 LT in June 2011.

2) SqX oscillates around zero from October to January, the maximum value of $\mathrm{SqX}, \sim 16 \mathrm{nT}$, was observed around 09.LT in December 2011. 


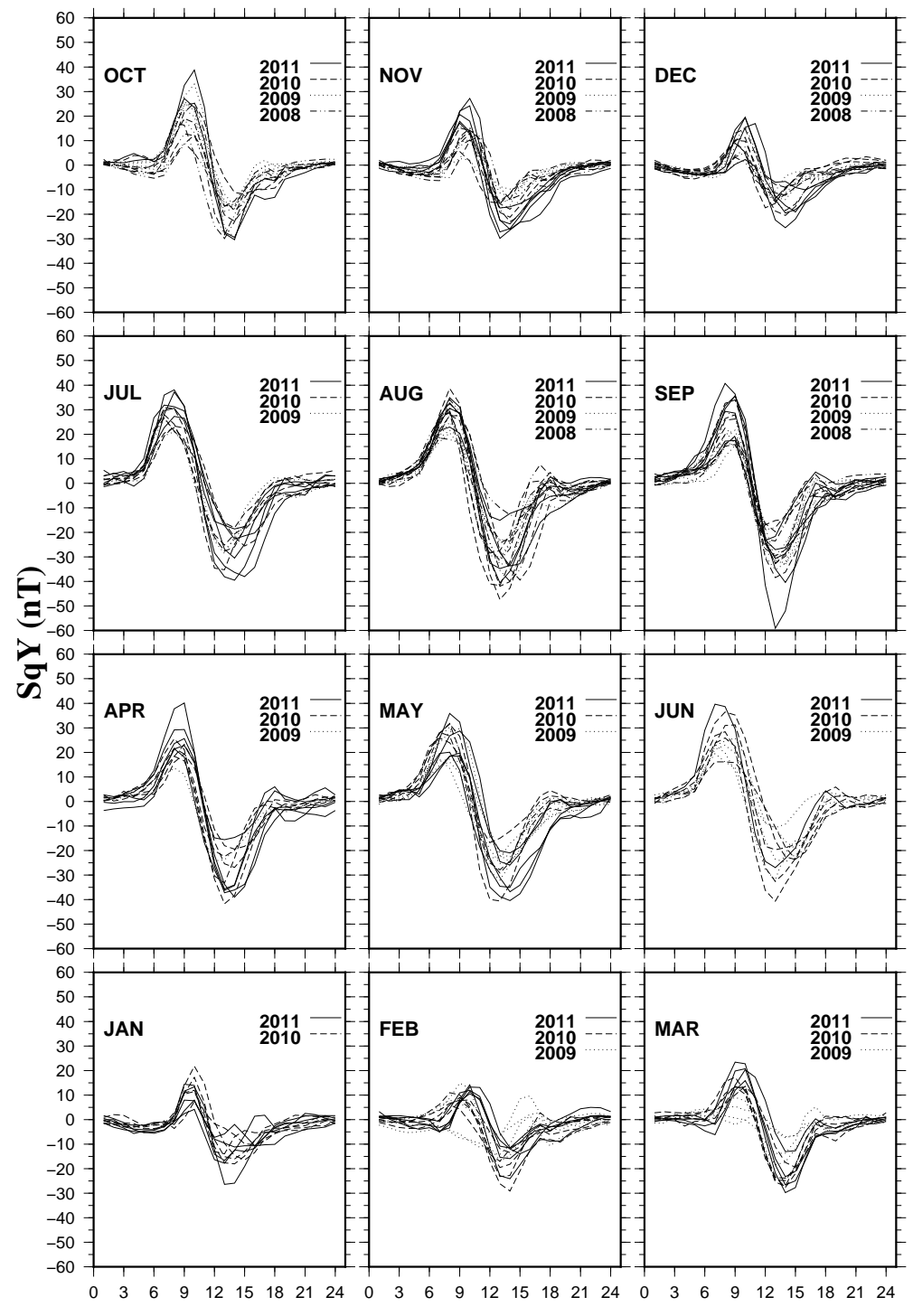

Local Time (HRS)

Figure $3 \mathbf{b}$ : The mass plot of diurnal variations of the $\mathrm{SqY}$ at Medea for all the available magnetic quiet days from August 2008 to December 2011.

3) $\mathrm{SqX}$ is negative in the morning and positive in the afternoon from July to September, the minimum value of SqX, -23 nT, was observed around 10.00 LT in August 2010 and the maximum value, $16 \mathrm{nT}$, was observed around 14.00 on September $1^{\text {st }} 2011$.

The first behavior corresponds to the ideal Sq current (see Figure 2), for a station below the focus, which is the case for Medea. The second behavior corresponds to a station near the focus of the Sq current, which can be slightly above or below the focus. The third behavior observed in summer is different; we will discuss later this point.

Figure $\mathbf{4 b}$ is similar to Figure $\mathbf{4 a}$ for the SqY. All the curves exhibit roughly the same pattern: a positive variation in the morning and a negative variation in the afternoon. This is exactly the behavior of the ideal Sq current. The exception is during FebruaryMarch 2009 when there is 


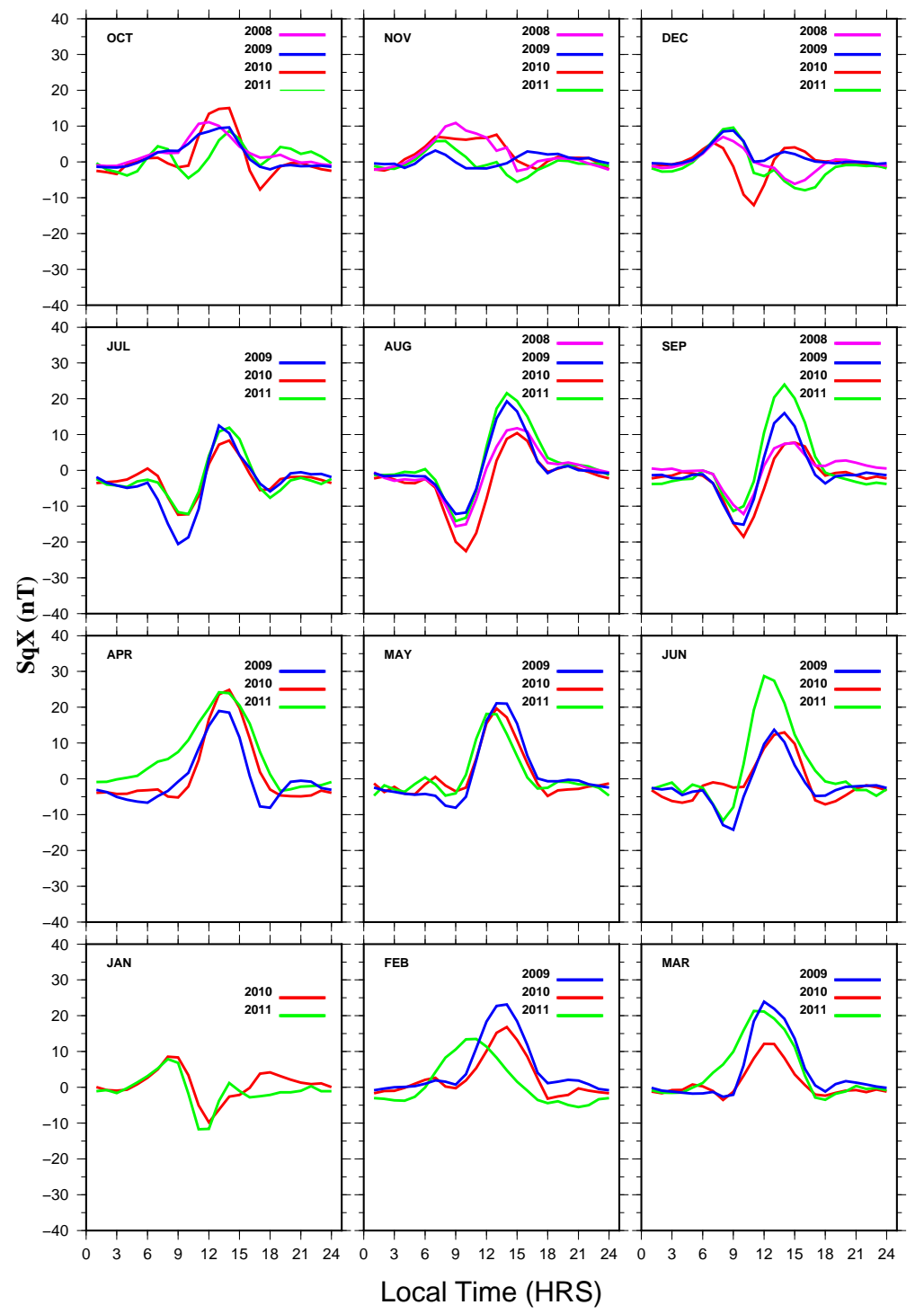

Figure 4a: Monthly mean diurnal variations of the SqX at Medea for each set of the five international quiet days of each month from August 2008 to December 2011.

apparently no southward current during the morning. The morning maximum values, $\sim 40 \mathrm{nT}$, was observed around 09.00-10.00 LT in June 2011, and the afternoon minimum values, $\sim-37 \mathrm{nT}$, was observed around 13.00 LT in August 2010.

Figure 5 gives the SqY reversal time for the whole period. The time of the reversal occurs always before noon. This figure shows that the local time of the reversal is in general between 10.00 LT and 11.00 LT during Summer months and after 11.00 LT in winter months. Except in February and Junuary 2009, the reversal time occur before 10.00 LT.

Figure 6 shows the amplitude of the morning maximum (dashed line) and afternoon minimum (block line). In general the amplitude of the afternoon minimum is greater than that of the morning maximum. We observe a seasonal variation: the highest values of the $\mathrm{SqY}$ are observed in summer and the lowest values in winter. The amplitude of SqY is increasing from 2009 through 2012, which 


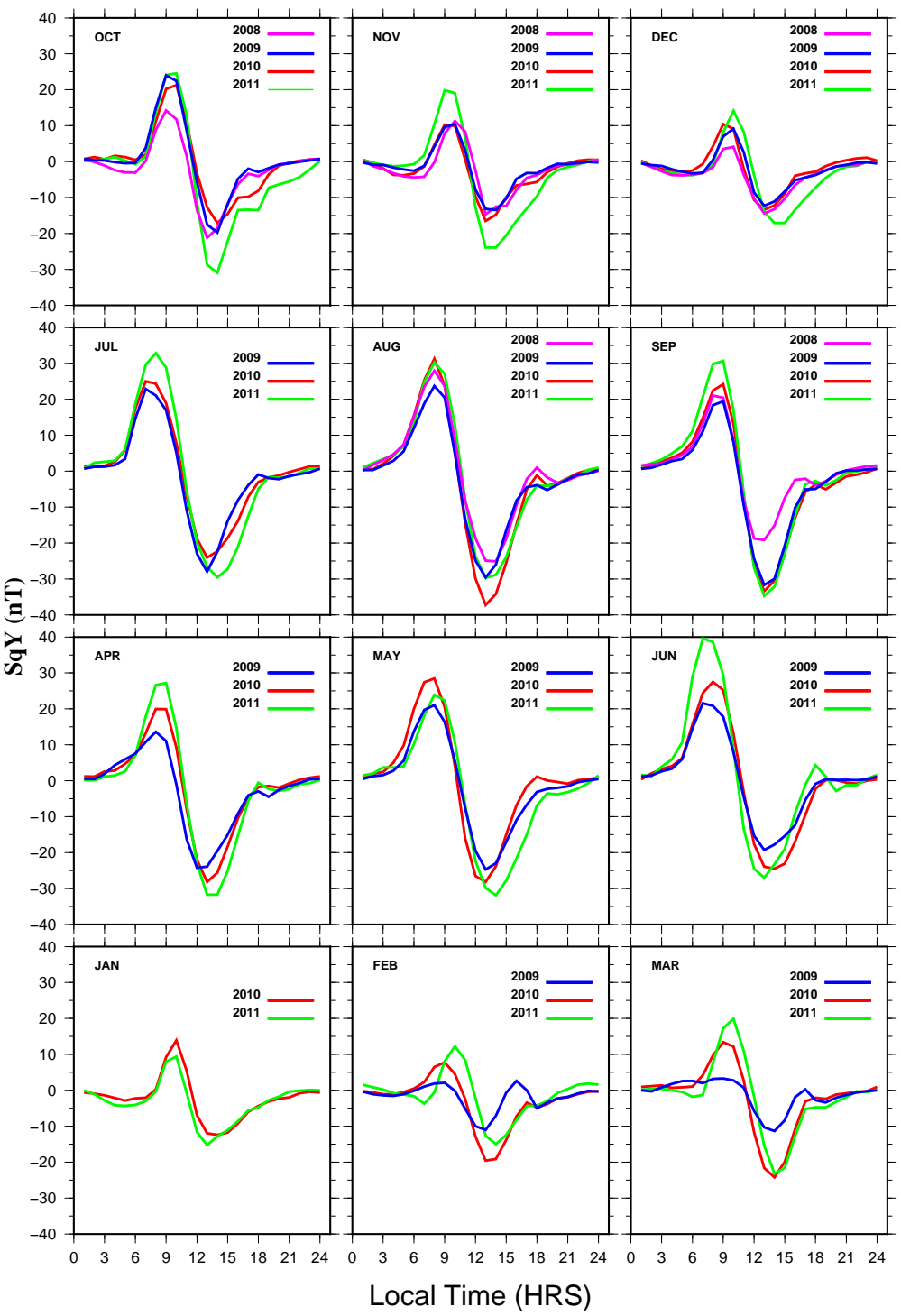

Figure 4b: Monthly mean diurnal variations of the SqY at Medea for each set of the five international quiet days of each month from August 2008 to December 2011.

represents the solar cycle effect.

\subsection{Seasonal variations}

Figure 7 illustrates the seasonal variations of SqX, (left side) and SqY (right side). The SqX exhibits roughly the same pattern for spring, summer and autumn with a maximum of the SqX around 20nT during the day. In summer and autumn, a small negative minimum (few $\mathrm{nT}$ ) is observed in the morning. During winter the SqX is very small $(<10 n T)$ and fluctuates. The SqY is similar for all the seasons with a maximum in the morning and a minimum in the afternoon. While the SqX maximum occurred in 2011, the maximum of $\mathrm{Sq}(\mathrm{Y})$ occurred earlier, i.e., in 2009 and 2010 . 


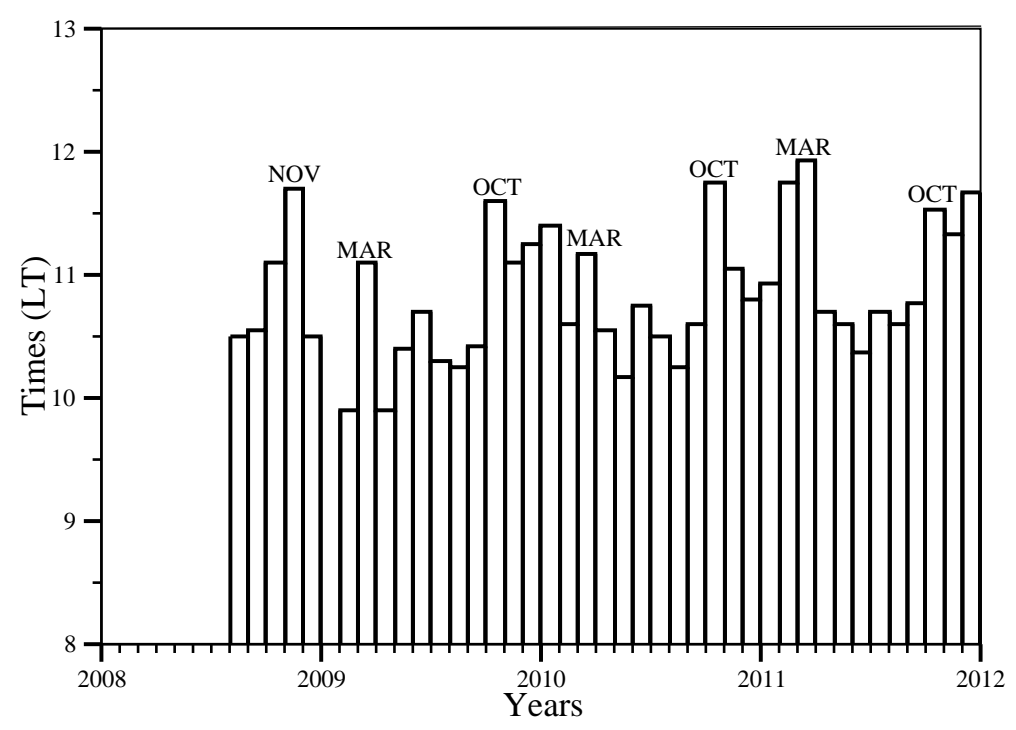

Figure 5: Times of the reversal of the SqY component at Medea from August 2008 to December 2011.

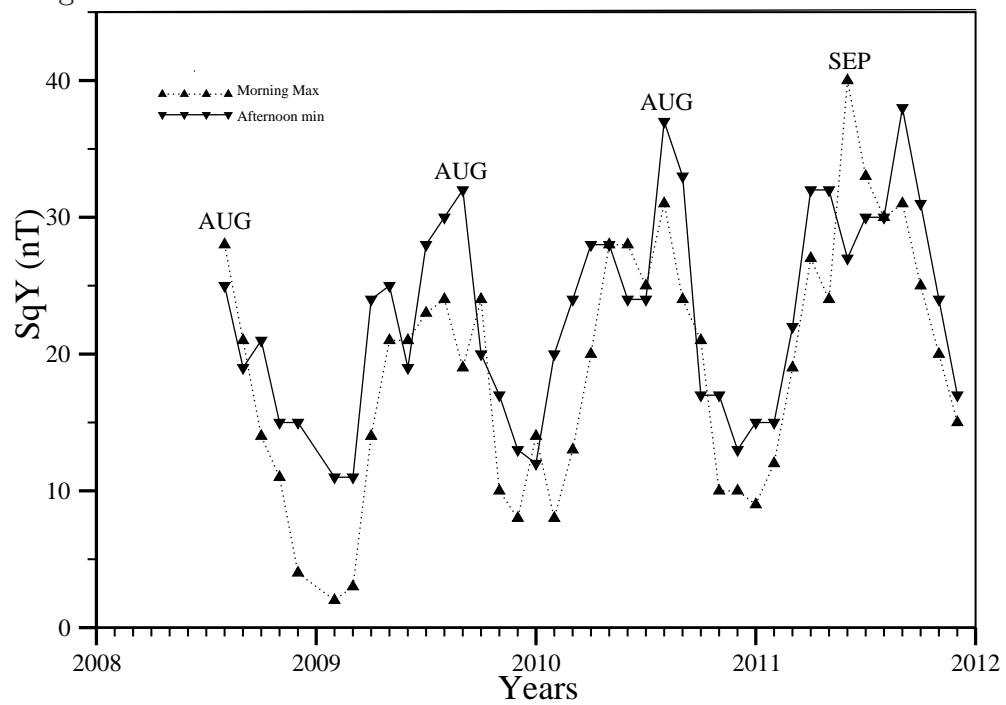

Figure 6: Amplitude of SqY maxima in the morning (dashed line) and afternoon (block line) of SqY at Medea from 2008 to 2011.

It is noted that these seasonal variations are superimposed on the day-to-day variations, which are particularly evident in SqX. The patterns of the seasonal average daily variations are consistent with the Sq current system in the northern hemisphere illustrated in Figure 2. The small amplitude $\mathrm{SqX}$ in winter can be understood by the fact that during this season, Medea is closest to the focus of the Sq current system, than during the other seasons.

Figure 8 shows the seasonal variations of SqX (left panels) and SqY (right panels). The variations of $\mathrm{SqX}$ in spring, Summer and autumn exhibit the dayside maximum roughly at the same time in 2009 and 2010. However, in 2011, the SqX dayside maximum occurs 2 hours earlier 


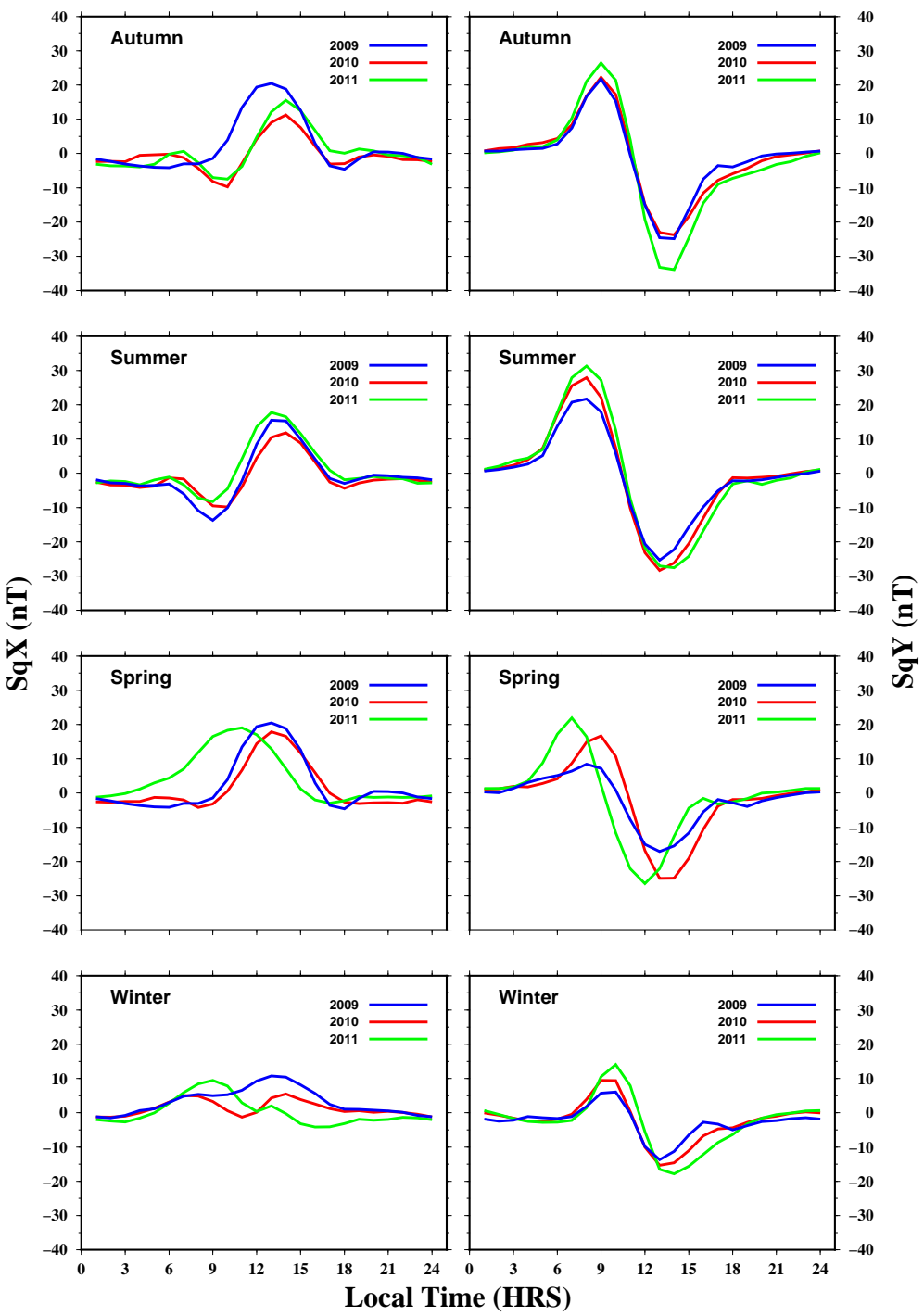

Figure 7: Seasonal variations of SqX (left column) and SqY (right column) at Medea from 2009 to 2011.From top to bottom each row represents the corresponding season for each year 2009, 2010 and 2011 respectively.

than that of in 2009 and 2010.

The seasonal variation in $\mathrm{SqY}$ is very large particularly in 2011.

\section{Discussion and conclusion}

The $\mathrm{Sq}$ variation in the $\mathrm{X}$ component observed at the Medea Observatory shows different patterns for different months and seasons (see Figure 3a, Figure 4a, Figure $\mathbf{7}$ and Figure $\mathbf{8}$ ). All these differences in shapes do not correspond to the "ideal" Sq current system (Figure 2) but correspond to some other equivalent currents systems represented by three models called $\mathrm{R}, \mathrm{T}$ and F (Mayaud, 1965). The left panel in Figure $\mathbf{9}$ shows the pattern of the R, T and F models and the right panel in the same figure shows the SqX current systems that are caused by each model. The current model R ("ideal Sq system") is a current system with oval or elliptical lines. The short 

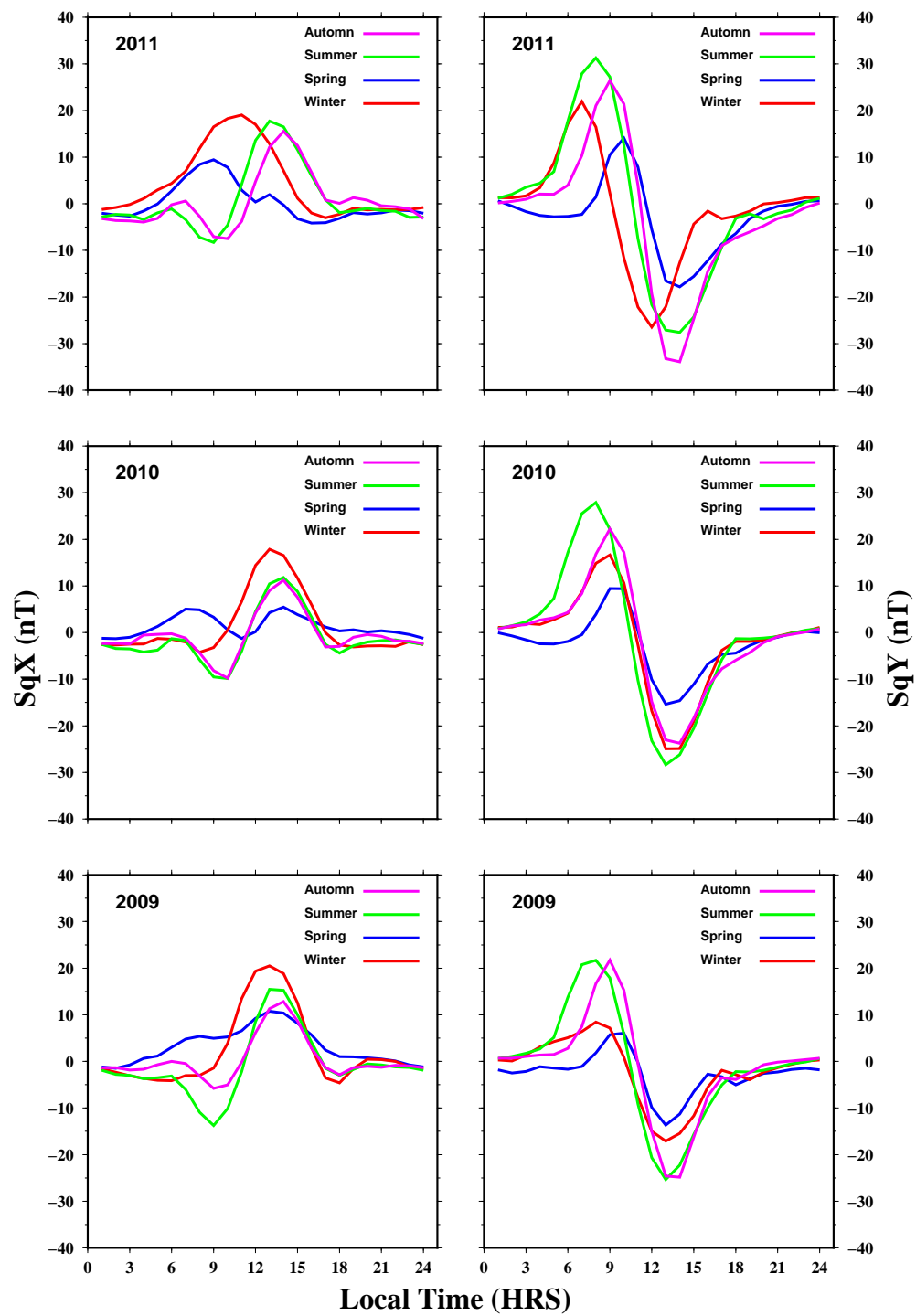

Figure 8: Seasonal variations of SqX (left column) and SqY (right column) from 2009 to 2011. From top to bottom each panel shows the four seasons of the year. Each figure shows 4 curves corresponding to the variation of either $\mathrm{SqX}$ or SqY over the 4 seasons (Winter, Spring, summer and autumn). From top to bottom each row represent the seasonal variation across each individual year

axis is north-south. Its focus is located at mid-latitudes. The model $\mathrm{R}$ has an inclination of the small North South axis which is no more directed North South as for the model T. In comparison with the model $\mathrm{R}$, the focus of the model $\mathrm{F}$ can be located at higher or lower latitudes. With a displacement of the focus toward the high latitudes, the variation at the focus is nil and is negative from either side. With a displacement of the focus toward low latitudes the effect is positive from either side. The $\mathrm{R}$ model causes no variation in $\mathrm{SqX}$ component at the latitude of the focus. However, at the either side of the focus, it causes a minimum pure (P-type form) above the focus and maximum pure (form type E) below the focus. At the Medea station, the effect caused by the $\mathrm{R}$ model is observed from February to June on diurnal and monthly variations. Indeed, from February to June, the SqX shows a form of type E (i-th maximum pure). 


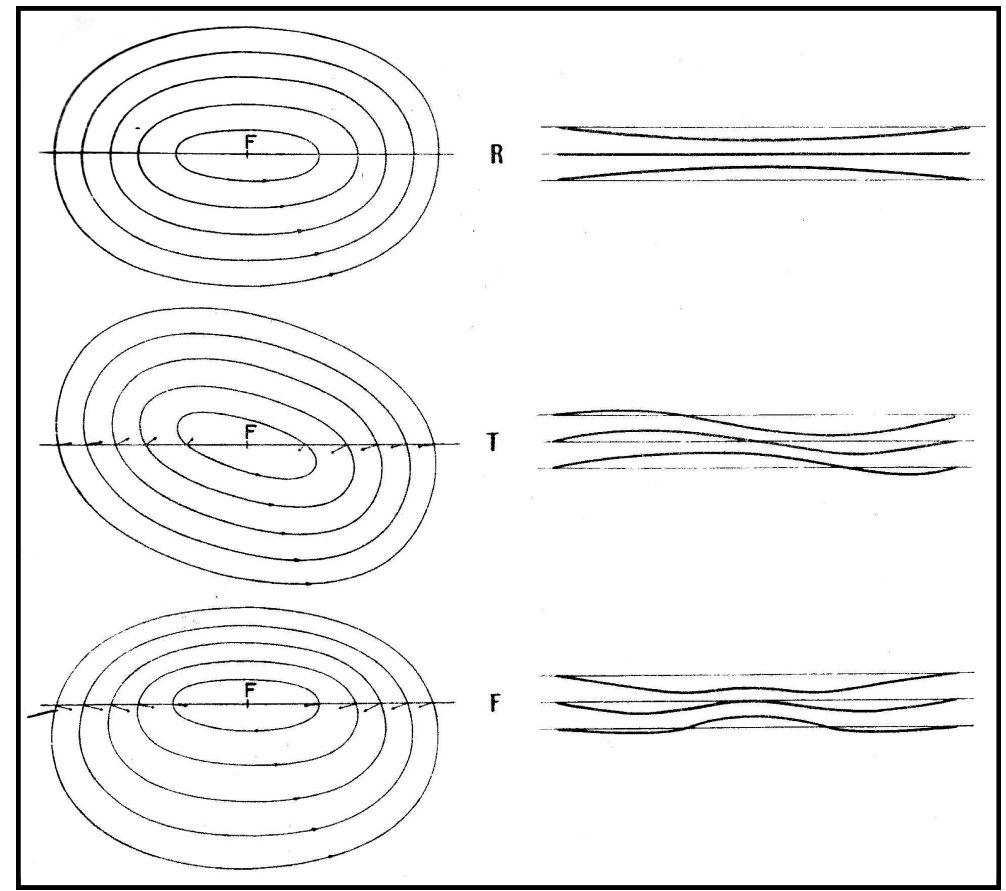

Figure 9: Seasonal variations of SqX (left column) and SqY (right column) from 2009 to 2011. From top to bottom each panel shows the four seasons of the year. Each figure shows 4 curves corresponding to the variation of either $\mathrm{SqX}$ or SqY over the 4 seasons (Winter, Spring, summer and autumn). From top to bottom each row represent the seasonal variation across each individual year

From July to September, we observe negative values in the morning and positive values in the afternoon sector. However, in summer and autumn we also observed a secondary minimum. The behavior of the SqX component corresponds to a transition between the type $\mathrm{P}$ and type E. This transition corresponds to the effects caused by the $\mathrm{T}$ current model. The $\mathrm{T}$ current model corresponds to the $\mathrm{R}$ model with an inclination of its short axis, which is more North-South. The effect of such a model on the SqX component consists of a maximum followed by a minimum (denoted as $T_{h}^{m}$ ) or a minimum followed by a maximum (denoted as $T_{l}^{m}$ ) (Mayaud, 1965). In the case of Medea, from July to September, the morphology of the curves corresponds to the Model T. In the morning sector the inclination of the current lines are moved to lower latitudes (i-e $T_{l}^{m}$ ).

The monthly average diurnal variations from October to January and the seasonal average Sq variations for the winter can be likened to the effects of $\mathrm{R}$ model at the latitude of the focus. This is due to the fact that in winter the focus of Sq current system is very close to the latitude of the Medea station.

The morphology of diurnal, monthly and seasonal variations of the East component, SqY, observed at the observatory Medea (see Figure 3b, Figure 4b, Figure $\mathbf{7}$ and Figure 8 ), consists of normal type, the "northern type ", with a eastward maximum in the morning followed by an westward minimum in the afternoon. It corresponds to the effect of the ideal Sq current model (Figure 2). The SqY component shows always the same behavior (Figure 6). Nevertheless there is an asymmetry: the amplitude of the morning maximum is smaller than the amplitude of the afternoon minimum. This asymmetry is more pronounced in summer than in winter. The disappearance of the morning peak is due to the abnormal diurnal pattern of SqY during March 
2009, probably not seasonal effect. According to Pham et al. (2011), the disappearance of the morning peak was observed at MBour every spring during 1996-2006. At Medea, on the other hand, the disappearance of the morning peak occurred only during March 2009. Thus, this is something different from what Pham et al. (2011) found at MBour. El Hawary \& al. (2012) reported on the disappearance of the northern Sq current system in the East African region during February 2009. Also, Yamazaki et al. (2012) reported abnormal Sq behaviors in the American and Asian sectors during FebruaryMarch 2009, following an unusually strong stratospheric sudden warming event. It is worth mentioning here that the abnormal SqY at Medea during FebruaryMarch 2009 could also be associated with the stratospheric sudden warming effect.

The seasonal variation in the zero-crossing time shown in Figure $\mathbf{5}$ is consistent with the seasonal variation in the local time of the Sq current focus reported by Campbell \& Schiffmacher (1986). These observations are due to the shift of the focus of Sq system to high latitudes. The variability of the position of the focus current system Sq has been widely studied. (Suzuki, 1973), using the same data as Mayaud (1965) from 68 stations across the globe, showed that the focus of Sq system moves in the northsouth direction through the seasons. Stening et al. (2005), using data from the Australian and Japanese stations, showed that the focus of the Sq current system moves in the meridional direction from one day to another. By studying the seasonal and annual variations of the Sq current systems, Takeda (1999 and 2002) showed that the longitude of the focus of Sq system evolves with the seasons and hours of the day. Malin \& Gupta (1977) highlighted that the longitudinal shift of the northern hemisphere focus is ahead of that of the southern hemisphere by $73 \pm 21$ minutes.

The afternoon minimum of SqY component in Medea (Figure 6) has a semi-annual variation. This behavior corresponds to the effects of the model with two vortex Sq current system, one in each hemisphere. Yamazaki et al. (2009) found that the equivalent Sq current system undergoes semi-annual variations that allow the maintenance of the model with two vortexes. They explained this semi-annual variation is due to diurnal tidal winds. Indeed, it has been widely established that the diurnal variation of the tidal wind plays a major role in the formation of the model of Sq equivalent current system with two vortexes (Maeda, 1955; Kato, 1956). The morning maximum amplitude has an annual variation. This amplitude is higher in the summer months compared to the winter months. Yamazaki et al. (2009) found that the annual variation of Sq current system is characterized by the existence of a single vortex. This uniqueness of the vortex is probably due to the fact that the current intensity is greater in the summer hemisphere than in the winter hemisphere. In the summer, the higher-latitude annual currents are westward in the Northern Hemisphere and eastward in the Southern Hemisphere, and thus the northern Sq current vortex is strengthened and the southern Sq current vortex is weakened. In winter, the higher-latitude annual currents are eastward in the Northern Hemisphere and westward in the Southern Hemisphere, and thus the northern Sq current vortex is weakened and the southern Sq current vortex is strengthened. The annual variation can be explained by seasonal variations of the ionospheric conductivity and the atmospheric tides (Mazaudier \& Blanc, 1982; Yamazaki \& Yumoto, 2012) and by the fieldaligned currents flowing from the summer to the winter hemisphere in the morning and reversely in the afternoon (Fukushima, 1979). Unfortunately, our two-dimensional approach does not allows us to discuss how much field-aligned currents contribute to the annual variations of Sq.

The amplitude of SqY is increasing from 2009 through 2012, which represents the solar cycle effect (Figure 6). They peaked in 2011, which corresponds to the rising phase of the solar cycle number 24 . It is generally accepted that the amplitude variations of the ionospheric electric currents 
varies linearly with the solar cycle (e.g Olsen, 1993). In an analysis, on a long series of data from many observatories on the globe, Torta et al. (2009) showed that the magnitude of the SqY component varies linearly with the solar cycle. Yamazaki \& Yumoto (2012), using a Fourier analysis for the data observed at Kakioka and Gnangara, showed a positive linear correlation between the solar cycle and the annual and semi-annual variations of Sq current system. A strong correlation between the amplitude of Sq and the solar cycle variations has also been demonstrated (e.g Pham et al., 2011). However, this correlation is not the same for all observatories, see table 2 by Pham et al. The three year data from Medea, are not sufficient for the determination of the solar cycle effect.

In conclusion, the analysis of regular variations of $\mathrm{Sq}$ at the latitude of Medea helped us to highlight the following features:

- A differences in the diurnal pattern of the northward component $\mathrm{SqX}$ at different months and seasons, which corresponds to the effects caused by a transition model $\mathrm{R}$ and $\mathrm{T}$. These could be due to the shift of the focus position, deformation of Sq current system and its invasion from an hemisphere to the other.

- An equinoctial asymmetry: The amplitude of SqY in autumn is higher than in spring.

- Abnormal SqY at Medea during February-March 2009 could be associated with stratospheric sudden warming effect.

- A mismatch of the SqY component: the amplitude of the afternoon minimum is greater than that of the morning maximum. The morning-afternoon asymmetry of SqY is probably due to the UT variation of the Sq current system. That is, the Sq current system $\sim 14$ UT is stronger than $\sim 8 \mathrm{UT}$.

These results show that using a single station one can integrate the average movement and deformation of Sq system. However, the results obtained from Medea are not enough on their own to understand the dynamics of the ionospheric electric current systems of the northern hemisphere. The addition of data from observatories in Europe and North Africa may enable us to perform a systematic and comprehensive study of equivalent current system and its transient variations due to solar activity in the sector Africa- Europe. However, using instant mapping the results from all the observatories around the world can indeed contribute to a better representation of Sq current system at the global scale.

\section{Acknowledgement}

we are especially grateful to Akacem Nouredine and Meziane El-Hadi, who have contributed to installing and maintaining the Medea Observatory.

The authors sincerely acknowledge a reviewer whose comments and advices have greatly contributed to improve the final form of this work.

\section{References}

Abbas, M., Zaharadeen,Y.J., Joshua,B., \& Mohammedi,S. 2013, Geomagnetic Field Variations at Low Latitudes along $96^{\circ}$ Magnetic Meridian. Int. J. Mar. Atmos. \& Earth Sci, 1(2), 96-109. 
Amory-Mazaudier, C. 1983, Contribution à létude des courants électriques, des champs électriques et des vents neutres ionosphériques des moyennes latitudes, variation régulière et variations perturbées, Études de cas à partir des observations du sondeur á diffusion incohérente de Saint-Santin en relation avec les observations du champ géomagnétique terrestre, Thèse de Doctorat d'État lUniversité Pierre et Marie Curie.

Bolaji, O. S., Adimula, I. A., Adeniyi, J.O., \& Yumoto, K. 2013, Variability of Horizontal Magnetic Field Intensity Over Nigeria During Low Solar Activity. Earth, Moon, and Planets, 110(1-2), 91-103.

Breit, G. \& Tuve, M.A. 1926,. A Test of the Existence of the Conducting Layer. Physical Review 28 (3): 554575.

Campbell, W. H. 1981, Annual and semiannual variations of the geomagnetic field at equatorial locations, J. Atmos. Terr. Phys., 43, pp. 607616.

Campbell, W. H. \& Matsushita, S. 1982 Sq currents: A comparison of quiet and active year behavior, J. Geophys. Res., 87(A7), pp. 53055308.

Campbell, W. H. \& and Schiffmacher, E.R. 1986, Correction to Quiet ionospheric currents of the Northern Hemisphere derived from geomagnetic field records, J. Geophys. Res., 91(A8), 90239024,

Campbell, W. H. 1989, An introduction to quiet daily geomagnetic fields, Pure Appl. Geophys., 131, pp. 315331.

Chapman, S. \& Bartels,J. 1940, Geomagnetism. Oxford University Press, 1049p.

Chapman, S. 1951, The Earths Magnetism, John Wiley, New York.142p.

Chulliat, A., Blanter,E., Le Moul,J.L.,\& Shnirma,M. 2005, On the seasonal asymmetry of the diurnal and semidiurnal geomagnetic variations. Journal of Geophysical Research 110.:doi:10.1029/ 2004JA010551.

Davis, T.N., Stolarik, J.D., \& Heppner, J.P. 1965, Pocket measurements of Sq currents at midlatitude. Journal of Geophysical Research. 70. pp. 5883-5894.

De Michelis, P., R. Tozzi, R., \& Meloni, A. 2009. On the terms of geomagnetic daily variation in Antactica, Annales Geophysicae, 27, 2483.

Doumouya, V., Cohen, Y., Arora, BR. \& K. Yumoto, K. 2003. Local time and longitude dependence of the equatorial electrojet magnetic effects, J. Atoms. Terr. Phys. 65:12651282.

El Hawary, R., Yumoto, K., Yamazaki,Y., Mahrous,A., Ghamry,E., Meloni, A., Badi, K., Kianji, G., Uiso, C.B.S., Mwiinga, N., Joao, L., Thomas Affluo, Sutcliffe, P.R., Mengistu, G., Baki,P., Abe, S., Ikeda, A., Fujimoto,A., \& Tokunaga, T. 2012, Annual and semi-annual Sq variations at $96^{\circ}$ MM MAGDAS I and II stations in Africa., Earth Planets Space, 64, 425432.

Fukushima, N. 1979, Electric potential between conjugate points in middle latitudes caused by asymmetric dynamo in the ionosphere, J. Geomagn. Geoelectr., 31, 401409.

Gauss, C.F. 1839, Allgemeine Theorie des Erdmagnetismus. Resultate aus den Beobachtungen des Magnetischen Vereins im Jahre 1838 (Gttinger Magnetischer Verein, Leipzig, 1839), pp. 152.

Hagan, M. E. \& J.M. Forbes, J.M. 2002, Migrating and non migrating diurnal tides in the middle and upper atmosphere excited by tropospheric latent heat release, J. Geophys. Res., 107(D24), 4754, doi:10.1029/2001JD0012361.

Hagan, M. E.,\& Forbes, J.M. 2003, Migrating and non migrating semidiurnal tides in the upper atmosphere excited by tropospheric latent heat release, J. Geophys. Res., 108(A2), 1062,doi:10.1029/2002JA009466.

Kato, S. 1956, Horizontal wind system in the ionospheric E region deduced from the dynamo theory of the magnetic Sq variation, II, J. Geomag. Geoelectr. ,8, 2437.

Kelley, M. C. 2009, The Earths ionosphere: Plasma physics and electrodynamics. Academic. Press. 556p.

Lloyd, H. 1861, On Earth-currents, and their connexion with the diurnal changes of the horizontal magnetic needle, Trans. Roy. Irish Acad., 24, pp. 115-141.

Maeda, H. 1955, Horizontal wind system in the ionospheric E region deduced from the dynamo theory of the magnetic Sq variation, I, J. Geomag. Geoelectr.,7, 121132, 1955.

Maeda, H. 1968, Variation in geomagnetic field. Space Science Reviews, 8(4), 555-590.

Malin, S., Gupta, J. 1977, The Sq current system during International Geophysical Year. Geophys. J. R. astr. Soc. 49, pp. 515529.

Matsushita, S. \& Campbell, W. H. 1967, Physics of geomagnetic phenomena, vol. 1, New York: Academic press, $302,1398 \mathrm{p}$

Matsushita, S., \& Maeda,H. 1965, On the geomagnetic solar quiet daily variation field during IGY. Annales Geophysicae 21, pp. 514544 .

Mayaud P. N. 1965, Analyse morphologique de la variabilité jour à jour de la variation journalire "régulière" Sr du champ magnétique terrestre, 2. L e système de courants CM (régions non polaires), Ann. Geophys., 21, pp. 514-544.

Mazaudier, C., \& Blanc,M. 1982, Electric currents above Saint-Santin, 2,Model, J. Geophys R.es.,8 7, $2465,1982$.

Mazaudier, C., \& Venkateswaran, S.V. 1985, Strange currents over Saint-Santin, Geophys. J. Res., 90, pp 9727-9735

Obiekezie, T. N., \& Obiadazie, S.C. 2013, The variability of H component of geomagnetic field at the African sector. 
Physical Review \& Research International, 3(2), 154-160.

Olsen, N. 1993, The solar cycle variability of lunar and solar daily geomagnetic variations, Ann. Geophys., 11, pp. 254262.

Olsen, N. 1997, Geomagnetic Tides and Related Phenomena in Tidal Phenomena, Lecture Notes in the Earth Sciences, vol. 66, edited by: Wilhelm, H., Zuern, W., and Wenzel, H.-G., Springer, 261274.

Pedatella, N. M., Forbes,J. M., \& Richmond, A.D. 2011, Seasonal and longitudinal variations of the solar quiet (Sq) current system during solar minimum determined by CHAMP satellite magnetic field observations, Journal of Geophysical Research., 116. A04317, doi:10.1029/2010JA016289. pp. 1-13.

Pham Thi Thu, H., Amory-Mazaudier, C., M. Le Huy, M. 2011, Sq field characteristics at Phu Thuy, Vietnam, during solar cycle 23: comparisons with Sq field in other longitude sectors, Ann. Geophys., 29. doi:10.5194/angeo-29-12011. pp. 1-17.

Price, A.T., \& Wilkins, G.A. 1963, New methods for the analysis of geomagnetic fields and their application to the Sq field of 1932-3, Philos. Trans. R. Soc. London, Ser. A, 256, pp. 31-98.

Rabiu,A.B.,Mamukuyomi, A.I. \& Joshua, E. O. 2007, Variability of Equatorial Ionosphere Inferred from Geomagenetic Field Measurements. Bulletin of the Astronomical Society of India, 35, 607-618.

Rabiu, A. B., Adimula, I.A., K. Yumoto, K., J.O. Adeniyi, J.O., \& Maeda, G. 2009, Preliminary results from the magnetic field measurements using MAGDAS at Ilorin, Nigeria. Earth, Moon, and Planets, 104(1-4), 173-179.

Rastogi, R. G., \& Iyer,K.N. 1976, Quiet day variation of geomagnetic Hfield at low latitudes, J. Geomagn. Geoelectr., 28, pp. 461479.

Richmond, A. D. 1989, Modeling the ionosphere wind dynamo: A review, Pure Appl. Geophys., 47, pp. 413435.

Richmond, A. D. \& Thayer, J. P. 2000, Ionospheric Electrodynamics: a Tutorial. American Geophysical Union, pp. 131146.

Richmond, A. D. \& Roble, R.G. 1987, Electrodynamics effects of Thermospheric Winds from the NCAR Thermospheric General Circulation Model, J. Geophys. Res., 92, 1236512376.

Stening, R. J. 1971, Longitude and seasonal variations of the Sq current system, Radio Sci., 6(2), pp. 133137.

Stening, R.J. 1995, Variations in the strength of the Sq current system. Annales Geophysicae 13, pp. 627632.

Stening, R., Reztsova, T., L.H Minh, L.H. 2005, Day-to-day changes in the latitudes of the foci of the Sq current system and their relation to equatorial electrojet strength. Journal of Geophysical Research 110, A10308. pp. 1-6.

Stewart B. 1882, Terrestrial magnetism, Encyclopaedia Britannica, 9th ed., Vol. 16, 159-184.

Schuster A. 1889, The diurnal variation of terrestrial magnetism, Philos. Trans. R. Soc. London Ser. A 180, 467518.

Suzuki, A. 1973, A new analysis of the geomagnetic Sq field. Journal of Geomagnetism and Geoelectricity, 25(3), 259-280.

Takeda, M. 1999, Time variation of global geomagnetic Sq field in 1964 and 1980. J. Atmos. Solar-Terr. Phys. 61, pp. 765774

Takeda, M. 2002, The correlation between the variation in ionospheric conductivity and that of the geomagnetic Sq field. J. Atmos. Solar-Terr. Phys. 64, pp. 16171621.

Torta, J. M., Curto,J. J., \& Bencze, P. 1997, Behavior of the quiet day ionospheric current system in the European region, Journal of Geophysical Research., 102, pp. 24832494.

Torta, J. M., Gaya-Piqu, L. R., Curto, J. J., \& Altadill, D. 2009, An inspection of the long-term behaviour of the range of the daily geomagnetic field variation from comprehensive modelling, J. Atmos. Sol.-Terr. Phys., 71, 14971510, doi:10.1016/j.jastp.2008.06.006.

Torta, J. M., Marsal, S., Curto, J.J., \& Gaya-Piqu, L. R. 2010, Behavior of the quiet day geomagnetic variation at Livingston Island and variability of the Sq focus position in the South American-Antarctic Peninsula region; Earth, Planets and Space, 62, 297307.

Van Sabben, D. 1964, North-south asymmetry of Sq, Journal of Atmospheric and Terrestrial Physics, vol. 26, no. 12 , pp. $1187-1195$.

Van Sabben, D. 1966, Magnetosphere currents associated with the N-S, asymmetry of Sq, J. Atmos. Terr. Phys., 28, 965.

Vassal, J. 1982, La variation du champ magnétique et ses relations avec I'iélectrojet équatorial au Sénégal Oriental. Ann. Geophys, 38, 347-355.

Vestine, E. 1947, The geomagnetic field, its description and analysis, Carnegie Institute, Washington Publ, 580.

Yamazaki, Y., Yumoto, K., T. Uozumi, Yoshikawa,A., \& Cardinal. M.G. 2009, Equivalent current systems for the annual and semiannual Sq variations observed along the $210^{\circ}$ MM CPMN stations, J. Geophys. Res.,114, A12320,doi:10.1029/2009JA014638.

Yamazaki. Y, Yumoto, K., Cardinal, M.G., Fraser, B. J., Hattori, P., Kakinami, Y., Liu, J. Y., Lynn, K. J. W., Marshall, R., McNamara, D., Nagatsuma, T., Nikiforov, V.M., Otadoy, R.E., Ruhimat, M., Shevtsov, B. M., 
Shiokawa, K., Abe, S., Uozumi, T., \& Yoshikawa, A. 2011, An empirical model of the quiet daily geomagnetic field variation. Journal of Geophysical Research: Space Physics (19782012), 116(A10).

Yamazaki Y, Yumoto K. 2012, Long-term behavior of annual and semi-annual Sq variations. Earth Planets Space 64:417-423.

Yamazaki, Y., Richmond, A. D., Liu, H., Yumoto, K., \& Tanaka, Y. 2012, Sq current system during stratospheric sudden warming events in 2006 and 2009, J. Geophys. Res., 117, A12313, doi:10.1029/2012JA018116.

Yizengaw, E., \& Moldwin, M.B. 2009, African Meridian B-field Education and Research (AMBER) Array. Earth Moon Planet 104 (1), pp. 237246. 